\title{
Trabajo y conflicto social. Los operadores en el Sistema de Responsabilidad Penal Juvenil de Mendoza, Argentina*
}

\author{
Patricia Gorri - Patricia Lecaro **

\section{Resumen} \\ El presente artículo intenta comprender el proceso de trabajo \\ en instituciones que albergan a jóvenes en conflicto con la ley \\ en un contexto de actualización legislativa y cambio \\ paradigmático, en torno a los derechos de los niños, niñas y \\ jóvenes en Argentina. Nos preguntamos qué implica ser \\ trabajador en una institución cerrada, cuáles son las dinámicas y \\ prácticas laborales, y de qué manera el conflicto social y el rol \\ represor de estas instituciones se hace visible en el discurso y \\ las prácticas de los trabajadores que cotidianamente conviven \\ con jóvenes transgresores. \\ Partimos del análisis de un conflicto específico como fue el \\ motín producido a fines de 2012, el cual sucede luego de varios \\ intentos y fugas, exoneración por primera vez de un trabajador \\ de la Unidad de Internación, y que evidenció la violencia en los \\ cuerpos y puso en tensión el derecho de los jóvenes y de los \\ trabajadores, en nuestro caso, los operadores del sistema.
}

\footnotetext{
* Artículo recibido el 3 de Abril de 2016. Aceptado el 26 de Julio de 2016.

** Patricia Gorri Licenciada en Administración Pública y Ciencia Política. Profesora Adjunta a cargo titularidad de Teoría Política II de la licenciatura en Ciencias Política y Administración Pública, y profesora JTP de Teoría Política de la Licenciatura en Trabajo Social; Mail: pgorri@yahoo.com. Patricia Lecaro, Licenciada en Sociología, profesora titular de estructura Social y Profesora Adjunta de Procesos Sociales Contemporáneos de la Licenciatura en Sociología. Facultad de Ciencias Políticas y Sociales. Universidad Nacional de Cuyo. Mail: patolecaro@yahoo.com
} 


\title{
Palabras clave
}

Trabajo - jóvenes en conflicto con la ley - instituciones cerradas.

\begin{abstract}
This paper attempts to understand the work in institutions are home to youth in conflict with the law in the context of legislative update and paradigmatic about the rights of children and young people in our country change. So, we wonder what means to be working in a closed institution; what are the dynamics and labor practices; how social conflict and the repressive role of these institutions is visible in the discourse and practices of workers who daily live with young offenders.

It is part of the analysis of a specific conflict as was the riot occurred in late 2012, which happens after several attempts and leaks, exoneration for the first time of a worker Hospitalization Unit, which showed violence on the bodies and stiffened the right of young people and workers, in our case, the system operators.
\end{abstract}

\section{Keywords}

Job - young people in conflict with the law - closed institutions.

\section{Trabajo y conflicto social. Los operadores en el Sistema de Responsabilidad}

\section{Penal Juvenil de la Provincia de Mendoza, Argentina.}

La investigación surge como parte de la experiencia profesional de trabajar en la Dirección de Niñez, Adolescencia y Familia (DINAF) del Gobierno de la Provincia de Mendoza, y de la participación en el proyecto de investigación acerca de Poblaciones Trabajadoras Extinguibles y Sujetos Colectivos en el Siglo XXI: Teoría y Praxis de Procesos de Trabajo desde una Ciencia Social Coproductiva y Experiencias Comparadas dirigida por Alberto L. Bialakowsky ${ }^{1}$.

\footnotetext{
${ }^{1}$ Proyecto: Poblaciones Trabajadoras Extinguibles y Sujetos Colectivos en el Siglo XXI: Teoría y Praxis de Procesos de Trabajo desde una Ciencia Social Coproductiva y Experiencias Comparadas. Secretaría de Ciencia y Técnica. Proyectos de Investigación Científica o de Innovación Tecnológica. Programación Científica 2011-2014, UBA.
} 
El objeto de análisis que se presenta en este artículo es un hecho puntal como fue el motín que se produjo el 30 de octubre de 2012 en la Dirección de Responsabilidad Penal Juvenil (DRPJ) $)^{2}$ de la Provincia de Mendoza.

Hubo siete fugas en el ex Cose y malestar del personal

Una revuelta de al menos ocho jóvenes alojados en la dirección del Sistema de Responsabilidad Penal Juvenil (ex Cose), dejó como saldo cinco operadores terapéuticos heridos, uno de ellos grave y 5 jóvenes que se fugaron. Los jóvenes decidieron apedrear al personal. Incluso uno de los trabajadores recibió un puntazo que lo dejó herido de gravedad. Los operadores reprimieron y golpearon a varios de los jóvenes y debió intervenir la policía provincial reprimiendo incluso con gases lacrimógenos a los operadores para evitar que terminara muerto alguno de los chicos. El conflicto se fue gestando en los meses previos donde se acumularon denuncias por parte de los jóvenes contra algunos operadores por malos tratos y violencia física y verbal. A su vez también el sindicato Asociación Trabajadores del Estado (ATE) denuncia los malos tratos que reciben los operadores por parte de los internos y la falta de operadores.

Luis Pérez, operador y delegado de ATE que también se encontraba ayer en el lugar, indicó: "Esta situación viene desde hace unos ocho meses. Se han hecho denuncias de los malos tratos que reciben los operadores por parte de los internos. Además faltan operadores. Deberían haber seis por guardia, pero hay sólo dos o tres". En cuanto a la fuga, se explicó que los jóvenes saltaron desde la medianera del edificio hacia la calle Río Juramento (cuyo tránsito se interrumpió por esta situación), cruzando también la tela metálica que "protege" el área. "Todo sucedió mientras los operadores estábamos reunidos en asamblea. Los directivos no fijan líneas claras sobre cómo debemos actuar nosotros. Hay un doble discurso", enfatizó Pérez, que tiene a su cargo 58 internos.

Por eso, sindicalistas, ministros y autoridades del Juzgado de Minoridad y Familia, de la DINAF (Dirección de Niñez, Adolescencia, Ancianidad, Discapacidad y Familia) y del SRPJ se reunieron ayer para tratar diversos temas en torno a este tipo de revueltas que

\footnotetext{
2 El Sistema de Responsabilidad Penal Juvenil (SRPJ) en 2012 congrega a dos direcciones: una de internación que es la Dirección de Responsabilidad Juvenil (DRPJ); y la otra es la Dirección de Medidas Alternativas a la privación de libertad (UMA, Unidad de Medidas Alternativas).
} 
De Prácticas y discursos/ Universidad Nacional del Nordeste/ Centro de Estudios Sociales

se producen con frecuencia. El principal punto a destacar es que se llegó a la conclusión de que es necesario contar con personal especialmente capacitado para actuar ante este tipo de situaciones.

El Ministro de Seguridad, Carlos Aranda, anunció que se hará en el Instituto de Seguridad Pública (ISP) un curso de 10 meses para formar a un grupo de profesionales que pueda encargarse de esta tarea. En este sentido, cabe recordar que hoy una de las problemáticas fundamentales -entre las tantas allí- es que los operadores que atienden a los internos cumplen una doble función: terapéutica y de seguridad.

"Se va a separar la figura del operador terapéutico de la del operador de seguridad. Hemos dejado indicado a la jueza María Amanda Fontemachi que, por ley, los operadores terapéuticos no hacen más requisas ni intervienen en conflictos o motines", explicó Raquel Blas, titular de ATE.

Otro punto a resaltar es que el Gobierno asumió el compromiso de llamar a concurso para el ingreso de nuevos operadores al ex Cose. "Ingresarían unas 20 personas más para cubrir el sistema de reemplazos y la cantidad real que tiene que haber por chico. En el sector de admisión, por ejemplo, que es el de menor complejidad tenemos 50 chicos amontonados y durmiendo en el piso. El Gobierno debe construir una unidad penal juvenil que realmente tienda a la rehabilitación y no al hacinamiento y a la marginación de los jóvenes", continuó Blas. (Diario Los Andes, Sociedad, 30/10/12).

Instituciones cerradas como la Dirección de Responsabilidad Penal Juvenil (DRPJ), cuya función de disciplinamiento y control social es explícita, dejan ver en hechos, como el anteriormente señalado, un capítulo más del conflicto social que se evidencia en los cuerpos heridos de operadores y jóvenes fruto de las graves agresiones cruzadas que inexplicablemente no terminaron en muertes.

Una vez controlada la revuelta, el sindicato hizo demandas respecto a condiciones de trabajo fundamentalmente en relación con la cantidad de operadores y a la determinación de las funciones específicas de su tarea. Por otra parte, organizaciones de DDHH interpusieron un habeas corpus a fin de garantizar la vida de los jóvenes alojados en la DRPJ. 
A los fines de este artículo recortaremos el análisis para enfocarnos en los "operadores", personal que está en contacto diario con los jóvenes en los "sectores"pabellones-. Es este personal, suerte de acompañante y carcelero, quien tiene en sus "manos" la potestad de organizar el tiempo y el espacio de los jóvenes, de administrar y dosificar el "castigo". Es el operador -y el regente-, el ejecutor de la pena y a su vez quien brinda atención y cuidados directos, construye vínculos con los jóvenes y también tiene la condición de trabajador estatal. Estas funciones contradictorias permean las prácticas, las psiquis y también el cuerpo del personal. El Estado y la sociedad depositan en estas personas el control social, la educación y resocialización de jóvenes transgresores. La falta de control y políticas de contención del personal afecta a la integridad física y mental de los jóvenes, y también de los trabajadores.

¿Qué implica ser trabajador en una institución cerrada? ¿Cuáles son las dinámicas y prácticas laborales? ¿De qué manera el conflicto social y el rol represor de estas instituciones se hace visible en el discurso y las prácticas de los trabajadores que cotidianamente conviven con jóvenes transgresores? ¿Son tan invisibles y excluibles como las poblaciones a su cuidado?

El trabajo de campo se realizó mediante entrevistas en profundidad a informantes claves como operadores, personal con responsabilidad de decisión en la institución, gremialistas y abogados de la Defensoría del Poder Judicial de la Provincia de Mendoza. Los mismos fueron seleccionados tomando como criterio de selección la función que cumplen, el conocimiento de la institución y de la problemática. Una característica relevante para la selección de los entrevistados fue que como mínimo hubieran sido parte de la institución cinco años, a fin de que su relato pudiera dar cuenta de la historia y la cotidianeidad de las tareas de control y cuidado que desempeñan los trabajadores.

La selección de metodologías cualitativas para el trabajo de campo se realizó por considerar que permite conocer mejor las prácticas y condiciones de trabajo en el encierro, que son inaccesibles con otras técnicas. Las entrevistas semiestructuradas nos permitieron conocer desde el relato de los propios actores y vislumbrar cuáles son los mecanismos disciplinatorios, el proceso de trabajo y las lógicas de poder al interior de 
De Prácticas y discursos/ Universidad Nacional del Nordeste/ Centro de Estudios Sociales

una situación de encierro. También hemos realizado el análisis de documentos, leyes, resoluciones y manuales de procedimientos a fin de conocer lo que el Estado y la institución en estudio plasman como la "norma", el deber ser en la atención y resguardo de derechos tanto para los jóvenes internados como para los trabajadores. Indagar respecto a lo escrito y lo dicho nos permitió poder visibilizar las condiciones reales de trabajo y "protección" en la institución.

\section{Algunas definiciones conceptuales}

La DRPJ ejecuta los mecanismos disciplinatorios, de resocialización, educación y de control que estipula el Estado para los jóvenes transgresores; sus funciones se han transformado en consonancia a los cambios de paradigma en la justicia penal juvenil, pasando del paradigma tutelar al de protección de derechos establecido por la ley $26.061 / 05^{3}$. Las prácticas al interior de la DRPJ reflejan lo complejo que es poder hacer efectiva la protección de derechos en instituciones disciplinarias que albergan a uno de los segmentos más excluidos de la sociedad, los jóvenes pobres y "transgresores", que son parte de las poblaciones extinguibles.

Como lo plantea Bialakowsky (2005:147 y 149), en la actualidad emergieron complejos y diversos procesos de extinción social, derivados de la estructura socioeconómica y de sus regulaciones institucionales. La población extinguible es aquella colocada en el curso del continuum de exclusión-extinción social, sobre la que se potencia la amenaza genérica de exclusión de la vida del sistema capitalista neoliberal, alejado ya de los patrones de modelos keynesianos, socialdemócratas o socialistas. Esta población se encuentra subordinada, sometida a regulaciones en las que se extrema, parafraseando a Espósito (2005: 21), la indistinción entre conservación y exclusión de la vida.

Se da un continuum de exclusión-extinción social, cuyas dinámicas relevantes constituyen procesos convergentes de desnormalización laboral y educativa, segregación espacial, nueva gestión punitiva (Wacquant, 2000) y fragilización de los cuerpos, entre otras dinámicas que contribuyen con el cambio sistémico.

\footnotetext{
${ }^{3}$ La Dirección albergaba en octubre de 2012 a unos cien jóvenes en conflicto con la ley, de entre 16 y 18 años.
} 
De Prácticas y discursos/ Universidad Nacional del Nordeste/ Centro de Estudios Sociales

La figura de la peligrosidad tiende a concentrarse en los jóvenes-pobres-urbanos como el perfil de población sobrante en una sociedad excluyente. El Estado penal despliega diferentes tácticas de barrido sobre lo indeseable o mantiene en márgenes claramente delimitados aquello que atenta contra determinado ordenamiento social. Este despliegue no se da porque estas poblaciones extinguibles constituyan una amenaza confrontativa abierta y explícita, sino, principalmente, por lo intolerables y atemorizantes que resultan a este ordenamiento estas producciones sociales segregadas (Bialakowsky, 2005). Las instituciones públicas estatales -la escuela, el juzgado, el instituto de menores, el hospital, etc. - no impiden los grandes procesos sociales de exclusión, en muchos casos los reproducen, en otros los profundizan. Por lo tanto, no puede pensarse un cambio sin una reflexibilidad cultural e institucional. En este sentido, los trabajadores estatales implicados resultan actores bifrontes: deben trabajar en la reparación de la urgencia, pero deben, al mismo tiempo, crear los dispositivos institucionales que protagonicen el freno al proceso social de exclusión (Bialakowsky, 2003).

En estos lugares donde, como plantea Zafaroni (2011: 3), "el poder punitivo se disfraza bajo múltiples discursos, confrontan prácticas, discursos teóricos y políticos que visibilizan que bajo el cambio de nombres estos lugares siguen cumpliendo su función de encubridores, invisibilizadores del conflicto social".

Coincidimos con Guemureman (2010: 2), quien tomando a Goffman (1998) plantea que las instituciones de encierro penal asumen un esquizofrénico doble mandato social: deben "castigar" pero "educando", deben "resocializar" pero manteniendo el "orden".

Como sostiene Bialakowsky (2003: 6), "la escuela, el juzgado, el instituto de menores, el hospital, se caracterizan por la particularidad de que su objeto de intervención resulta ser un hombre o específicamente el trabajo de un hombre sobre otro hombre". Los trabajadores -los operadores en nuestro caso- son quienes en su proceso cotidiano de trabajo reeditan relaciones sociales de poder y dominación legalizadas y estandarizadas por normas institucionales, que hacen efectiva la pena y la 
De Prácticas y discursos/ Universidad Nacional del Nordeste/ Centro de Estudios Sociales

resocialización, el cuidado y el castigo, y de los cuales se vuelven inexorablemente cómplices y víctimas.

El proceso de trabajo en estas instituciones conlleva elementos propios de una producción masificada fordista, explicitados en fenómenos observables como rutinización, división de las tareas, trabajo individual, especialización como paradigma dominante (...). Los resultados se traducen en procesos de mortificación que se imprimen en el padecimiento del trabajador y de su sujeto de trabajo. La dominación organizativa sostiene cotidianamente los procesos de trabajo reproductores de la exclusión, intensificando a su vez el sufrimiento y la mortificación de sus integrantes. Por otra parte, la imposibilidad del reconocimiento consciente del padecimiento de ambos actores, conlleva a la obturación de la capacidad reflexiva acerca del proceso de trabajo y de la propia participación del trabajador en la reproducción de métodos y prácticas violentos (...). El padecimiento además de su significación en tanto sufrimiento, adquiere "carácter instrumental" formando parte de la estructura de poder y regulativa. El proceso social de trabajo que subyace en la reproducción y profundización de la exclusión, se sustenta en una compleja trama de silencios sociales, que sostiene la posibilidad de que los dispositivos perduren a través del tiempo con una funcionalidad silenciada (Bialakowsky, 2003: 15).

\section{El Sistema de Responsabilidad Penal Juvenil}

El SRPJ es el órgano encargado de implementar los cambios de la ley 2.6061/05 de Protección Integral de los Derechos de las Niñas, Niños y Adolescentes, la que resignifica los "Institutos de menores", "Centros socioeducativos" y el "Sistema de responsabilidad penal juvenil" como dispositivos socioeducativos de régimen cerrado. En este sentido, las políticas públicas que de esta ley se desprendieron y se han articulado a través de la Secretaría Nacional de Niñez, Adolescencia y Familia -SENAFtienen por objetivo la resocialización de los jóvenes en conflicto con la ley centrada en un eje socioeducativo.

A través de las nuevas Pautas para las Políticas Públicas de Niñez y Adolescencia (2008: 15)se privilegia "la intervención centrada en el eje socio-educativo para que 
estos jóvenes desarrollen su capacidad de ejercer derechos, de respetar los derechos de los otros y de asumir obligaciones que les permitan llevar adelante un proyecto de vida ciudadano. De esa manera se van dejando atrás algunos enfoques, muy arraigados en el sistema y tributarios de la doctrina minoril, que tienden a ver en el adolescente infractor a un sujeto destinatario de un tratamiento psicoterapéutico compulsivo" ${ }^{4}$.

Así, diversas propuestas de intervención integral establecen recomendaciones y líneas de acción a ser aplicados en las diversas provincias. El acta compromiso Una política respetuosa de los DDHH para los adolescentes infractores de la ley penal, a la cual Mendoza adhirió en 2008, promueve el fortalecimiento y diseño e implementación de programas destinados para que la privación o restricción de la libertad dispuesta por autoridad judicial no implique la vulneración de otros derechos; (...) garantizar a los jóvenes incluidos un trato digno, educación, recreación, salud, adecuada vinculación con la familia y la comunidad, el derecho a ser oídos y, en su caso, condiciones dignas de alojamiento ${ }^{5}$.

En cuanto a la función del SRPJ, el Estado lleva adelante el "tratamiento" de estas poblaciones con diversas estrategias basadas en prácticas de seguridad estática y/o prácticas de seguridad dinámica ${ }^{6}$. Las prácticas de seguridad estática son las que visibilizan la falta de integración de las áreas de trabajo de los centros en un proyecto común y la ausencia de un plan de capacitación sistemático del personal. Estas prácticas se centran en el control físico de los residentes y en la idea de su contención como eje central de las intervenciones. La comunicación del personal con los residentes toma, generalmente, la forma de amenazas y de presiones que se vehiculizan a través de un argot carcelario para la obtención de ventajas a partir del dominio sobre los más débiles. Esto no solo se da entre operadores y jóvenes, sino entre los jóvenes entre sí,

\footnotetext{
${ }^{4}$ Nuevas Pautas para las Políticas Públicas de Niñez y Adolescencia, en el documento Adolescentes en el sistema penal. Situación actual y propuestas para un proceso de transformación, Fondo de las Naciones Unidas para la Niñez, Adolescencia y Familia, 2008. Impreso en Argentina.

${ }^{5}$ Acta Anexo II, en el documento Adolescentes en el sistema penal. Situación actual y propuestas para un proceso de transformación, Fondo de las Naciones Unidas para la Niñez, Adolescencia y Familia, 2008. Impreso en Argentina.

6 Documento Adolescentes en el sistema penal. Situación actual y propuestas para un proceso de transformación, Fondo de las Naciones Unidas para la Niñez, Adolescencia y Familia, 2008. Impreso en Argentina.
} 
así muchas veces quienes se constituyen como líderes en los pabellones son los que "amenazan, se imponen" a sus compañeros. Por lo general, se instala de esta manera un nivel de violencia intra-institucional relativamente alto.

Las prácticas de seguridad dinámica, por su parte, se centran en la educación como misión prioritaria para posibilitar el desarrollo de los proyectos de vida de los residentes, promueven un trato interpersonal basado en el respeto y en el cuidado de los otros e implican que las intervenciones de todo el personal deben constituir un ejemplo, en este sentido, para que los jóvenes puedan paulatinamente asumir como propio este modo de relación. Para la implementación de dichas prácticas, hay que contar con personal especializado y suficiente, entre el que adquiere especial relevancia el equipo de operadores. Pues si se pretende que la administración formal de la vida en los centros no represente para los adolescentes un corte abrupto entre las normas de la sociedad circundante y las normas internas de la institución, resulta necesario que los operadores trabajen con los adolescentes hábitos de convivencia a través de rutinas y actividades cotidianas; también que tomen a su cargo la tarea de prevenir y mediar en los conflictos a través de estrategias socioeducativas, transfiriendo a los adolescentes herramientas para su resolución de manera no violenta ${ }^{7}$.

\section{La estructura de personal de la Dirección de Responsabilidad Penal Juvenil}

Está a cargo de un director designado por el Poder Ejecutivo Provincial, es decir que es un funcionario político que cuenta con una estructura administrativa de gestión, un equipo de profesionales -trabajadores sociales, abogados, médicos, psicólogos, psiquiatras, psicólogos sociales, sociólogos, etc.- y el personal que cumple tareas de control, disciplina y acompañamiento permanente de los jóvenes albergados: los operadores terapéuticos. Esta figura existe en otras unidades penales juveniles con diversas denominaciones: celadores, maestros. La denominación de operadores terapéuticos remite claramente a una visión cuasi médica de abordaje de tipo "patológico" respecto a la población con la cual se trabaja. Se encargan de la

\footnotetext{
7 Documento Adolescentes en el sistema penal. Situación actual y propuestas para un proceso de transformación, Fondo de las Naciones Unidas para la Niñez, Adolescencia y Familia, 2008. Impreso en Argentina.
} 
seguridad, el orden, son quienes organizan, reglamentan, vigilan y distribuyen el tiempo y el espacio de los jóvenes en el encierro. Sin embargo, el personal desde 1998se autoidentifica más con la denominación operador socioeducativo -la cual remite al programa Centro de Orientación Socio Educativa-.

Teniendo en cuenta la estructura organizacional, se encuentran por orden de responsabilidad el jefe de internación, los regentes y subregentes, y los operadores, a los que hay que sumarle los guardias de seguridad externos a los sectores.

En la provincia de Mendoza, estos trabajadores gozan de estabilidad laboral desde el momento de su ingreso, no es posible que el personal contratado cumpla funciones de ningún tipo dentro del DRPJ, a lo que se le suman tres ítems de retribución salarial por riesgo -ellos lo conocen como el 017, el 035 o ítem COSE- que triplican el salario respecto al resto del personal del Estado provincial. Estos ítems los perciben también el personal administrativo y profesional.

Los operadores gozan de estabilidad laboral que si bien es deseable y legítima por cierto, tensiona los derechos adquiridos como trabajador público y los derechos de los jóvenes. En 2012 se dio por primera vez la exoneración de un operador por maltrato hacia los jóvenes. Es muy difícil lograr una exoneración o al menos un traslado a otra dependencia, porque pierden el ítem COSE8 y, en general, son derivados a actividades fuera del contacto con los jóvenes, lo cual recarga al personal de los sectores y por el costo de cada agente es difícil lograr nuevos ingresos y, a su vez, contribuye a complejizar el clima institucional.

\subsection{El ingreso como operadores}

Hasta 2012 no había una definición explícita del perfil de los operadores. A partir del motín, el perfil que elabora el gremio en conjunto con los directivos establece que para

\footnotetext{
${ }^{8}$ COSE: Centro de Orientación Socio Educativa, nombre anterior de la Dirección y por el cual es más conocido. Nota: así se llamaba anteriormente la Dirección de Responsabilidad Penal Juvenil, Centro de Orientación Socio Educativa, haciendo hincapié en la educación y acompañamiento del joven en conflicto con la ley. Aun hoy se refiere a esta institución como ex COSE.
} 
el ingreso se debe contar con ciertos requisitos: tener entre 25 y 40 años de edad; nivel educativo secundario completo; no puede trabajar si hay un familiar directo en la institución; ser una persona con anticipación, planeamiento, con una ansiedad que le sirva y que no lo paralice frente a ciertas situaciones, no ser impulsivo; tener control de la agresión y de los impulsos.

"En el sector de máxima o mediana seguridad se busca una persona que tenga experiencia en (no es excluyente) a diferencia de aquellos que estén encargados de sectores de mediana a mínima seguridad, su perfil debe ser más terapéutico. Estos últimos operadores son llamados en la institución operadores terapéuticos: de contención psicológica, afectiva, física. Este operador trata de contener al menor, por eso se lo llama terapéutico9. Muchos se desempeñan o se han desempeñado en agencias de seguridad o como patovicas10 de boliches de la provincia".(Entrevista a representante gremial).

En los últimos ingresos de personal, los representantes gremiales y el cuerpo de psicólogos de la institución sostienen que se intenta mejorar el perfil de los ingresantes.

"En las últimas tandas, yo estuve ahí presenciando el tema del llamado que se hizo para los operadores y bueno, lo que uno busca es esto, de tratar que tengan un perfil empático, que puedan ponerse en el lugar del otro, que no utilicen la violencia como medio educativo. Yo me basé mucho más en el rugby porque lo conozco, entonces yo los iba eligiendo, los nuevos estos, la mayoría son jugadores de rugby, porque el rugby tiene, los tipos que juegan al rugby

\footnotetext{
${ }^{9}$ Quien entre 2007 y 2011 fue coordinadora técnica describe cómo sería el operador ideal. En sus palabras: en realidad el operador ideal no existe en la institución, él debe hacer su trabajo sin dejar de lado lo terapéutico, es decir atender también al menor en lo psicológico, en lo afectivo, en lo físico... Tiene que existir una relación de respeto entre el operador y el joven, sin llegar a ser una persona autoritaria. El operador es un modelo para el joven a nivel de imagen o de identificación masculina porque, en general, estos chicos en sus casas no tienen esta figura que sería la de un padre, para ellos la figura de la casa es la madre y el padre una imagen ausente. Por eso es bueno que este modelo que no han tenido antes sea una persona lo suficientemente flexible como para poder mantener su autoridad, pero que tampoco sea un ogro para los jóvenes, es decir, se debe buscar un equilibrio entre ambas personalidades (García Ocanto, 2006).

${ }^{10}$ Patovicas: personas que custodian y brindan seguridad privada en las entradas de los locales bailables nocturnos en la provincia.
} 
tienen como una cierta cofradía y ellos se manejan socialmente como se manejan en la cancha, tienen vínculos que arman, que son muy compañeros. Entonces lo que necesitás adentro del COSE es eso, porque si vos dejaste solo a tu compañero, es como los bomberos, la policía, podés terminar muy mal, entonces ahí teníamos problemas de golpizas que había hacia los operadores, de motines y todo esto, porque bueno, el otro compañero como que se quedaba estático, no sabía qué hacer y no estaba en eso de pendiente de su compañero. Coincidíamos todos que estos hombres que venían de hacer estos deportes eran buenos para trabajar, primero por las estructuras de ellos, que son grandotes... y segundo por esa forma de ver por ahí las cosas, que no las ven por el lado de la violencia, a pesar que uno crea que el rugby es violento. $Y$ creo que la primera semana una cosa así hubo, un intento de fuga y uno de estos muchachos a los que nosotros habíamos apostado lo taclea al pibe, en vez de golpearlo, que en otro momento; o sea, lo taclea el muchacho nuevo, viene uno de los viejos, el muchacho ya lo tenía totalmente reducido en el piso, le patea la cabeza, entonces el nuevo le dice con qué necesidad si ya lo tengo reducido, entonces descargar por ahí la violencia en el pibe, si cuando lo redujo no había necesidad, eso es lo que queríamos cambiar". (Entrevista a representante gremial).

Es fuerte la impronta de apostar a lo grupal de manera defensiva contra los jóvenes. Si bien es indiscutible la peligrosidad de varios de los internos, en ningún lugar del relato se prioriza la función socioeducativa respecto a la contención de los jóvenes.

La dominación organizativa (Bialakowsky, 2003) está presente en el perfil del operador definido y que reproduce el paradigma tutelar. Los cambios normativos, de denominación, no se plasman en una capacidad reflexiva acerca del proceso de trabajo de los operadores; son los mismos funcionarios del Poder Ejecutivo y Judicial, profesionales especializados, delegados gremiales, quienes elaboraron este perfil para el ingreso de nuevos operadores con una concepción de seguridad estática y que sostiene la práctica defensiva con respecto a los jóvenes. El perfil definido poco y nada 
dice de una concepción de seguridad dinámica que tienda al objetivo socioeducativo para la resocialización.

\subsection{Las condiciones de trabajo}

En la investigación hemos realizado entrevistas que nos permiten conocer en parte cómo es trabajar en contextos de encierro y cómo se definen las actividades que desempeñan los operadores.

"Bueno, en realidad, el Cose tiene una historia bastante amplia; el Cose fue el Reta, nosotros le seguimos llamando el Cose, porque para nosotros, los empleados, uno crea por ahí un cariño con el lugar en el que uno trabaja, y lo seguimos considerando eso, un Centro Educativo, no como ahora que es la Dirección de Responsabilidad Penal ${ }^{11}$. A nosotros ya nos suena eso como un correccional. Así que inconscientemente, calculo yo, que nosotros, los empleados, le seguimos llamando el Cose; pasan los años, primero fue Sistema de Responsabilidad con la nueva ley y después pasó a ser ahora la Dirección, y para nosotros sigue siendo el Cose". (Entrevista a operador).

"Vos viste... estamos siempre al palo, no hay tiempo para nada, faltan operadores. Se supone que somos uno por cada 5 internos y en realidad estamos, por turno, 4 en cada sector. Esto cambia cuando hay horario de visitas porque si bien hay requisas, hay que estar muy atento a que las visitas no les pasen nada, o a los que se nos deprimen y sin aviso alguno intentan suicidarse". (Entrevista a operador).

\footnotetext{
${ }^{11}$ La ley 6.354/95 pone fin al programa correccional e histórico Instituto Reta, que nació como apéndice del Dirección del Menor cuando terminaba el proceso militar en la Argentina (1983) y cuyo espíritu era la asistencia a menores en situaciones de abandono y entre ellos, con el mismo método, también se asistía a aquel que había delinquido. El paradigma de la protección integral exigió la formulación de políticas públicas universales para las que los niños y jóvenes son sujetos de derecho, y el sistema judicial debería tratar con Juzgados específicos la problemática de los jóvenes en conflicto con la ley. En este contexto se conforma el Centro de Orientación Socio Educativa (COSE), una estructura que posibilitara la aplicación de métodos terapéuticos y educativos, entrenamiento laboral, integración familiar, habilidades sociales vinculadas a la resocialización. En el 2005 se modificó la estructura funcional del Programa Centro de Orientación Socio Educativa y se reemplazó por el Sistema de Responsabilidad Penal Juvenil (SRPJ), cuyo objetivo fue ofrecer alternativas al sistema penal que permitiesen abordar a adolescentes y su familia desde una perspectiva de adquisición progresiva de responsabilidades.
} 
Los entrevistados cuentan no solo parte de la historia de la institución, sino también describen cuál es la tarea o función que los operadores creen es su rol principal: ser operadores socioeducativos. Otras tareas que deben cumplir los trabajadores son despertar a los jóvenes en la mañana, hacer un recuento de los ellos cuando es necesario, realizar el control del aseo tanto de los chicos como del sector, verificar la asistencia a sus diferentes actividades diarias -ir a la escuela, a talleres, recreación-, como también realizar el traslado de los mismos a juzgados, al hospital y deben informar a sus autoridades sobre el comportamiento de los internos que están a su cargo.

En el sector de máxima seguridad, como la palabra lo dice, los operadores deben controlar más el tema de la seguridad; este sector es el único que tiene control de guardia policial, pero se encuentra fuera del sector, solo en los perímetros externos del pabellón. Es preciso aclarar que los operadores no portan armas de ningún tipo, lo único que llevan es una radio, un libro de vida, una lapicera, las llaves de las celdas y las esposas $^{12}$.

Todas estas actividades expresan la división y rutinización de tareas, acentuando un dispositivo de disciplinamiento no solo para los jóvenes, sino también para los trabajadores.

\subsection{El trabajo de administrar el encierro. El ruido de las rejas: 24 hs}

"Yo siempre cuento mi experiencia que la hice como pasante, que fue mi primera entrada al COSE y lo que más me marcó fue el ruido de las rejas. Y yo hablaba con una licenciada en la Facultad y ella me decía que ella no lo pudo tolerar, ella no puedo tolerar más que nada el ruido, es que te queda muy marcado el ruido de las rejas, hay

\footnotetext{
12 En general es muy buena la relación, pero es un relación de respeto, en donde el operador llama a los jóvenes por su apellido y los acompañan en las actividades que realizan, pero siempre estableciendo una distancia; el operador debe hacerse respetar en todo momento porque si no, estos chicos los pasan por encima y esa no es la función que deben cumplir. Es decir, no se puede hablar de una relación de amistad porque no es esa la función que deben cumplir, pero sí se observa un buen trato y diálogo. Es buena, ellos -internos- tienen claro que dependen de los operadores, igual hay que cuidarse porque hay cada uno que mamita, no podés confiarte ni darles la espalda (Zambrano, 2009).
} 
De Prácticas y discursos/ Universidad Nacional del Nordeste/ Centro de Estudios Sociales

un olor especial, hay cosas...vos entras y notás el olor del encierro, es increíble".(Entrevista a operador).

"Están 24 horas en la misma situación que los chicos, entonces por ahí eso es desgastante psicológicamente, lo único por ahí... Yo tengo un compañero que me dice siempre: 'Yo soy el que voy a hacer todas las compras, porque no me banco estar las 24 horas'; entonces le encargamos cigarrillos, le encargamos gaseosa, no importa que quede como el ekeko13, pero él sale, sale ese ratito porque no se banca las 24 horas estar ahí". (Entrevista a operador).

\subsection{Las relaciones personales y la salud de los operadores}

A través de las entrevistas pudimos vislumbrar cosas que todos nombraban desde el lugar que ocupan ya como trabajadores, defensores judiciales o personal directivo de la institución. En mayor o menor medida refirieron a las relaciones familiares o a la vida familiar de los operadores y también a su salud.

"Hay mucha, mucha adicción, no solamente a las drogas, sino al alcohol, al tabaco. A mí me ha pasado que yo por ahí no lograba entender y decía le estamos enseñando a los chicos algo y era una dicotomía total. Entonces, bueno, empiezan a surgir esas cosas".(Entrevista a operador).

"Bueno, tenemos esto, por ejemplo, el poco sostenimiento de los matrimonios, de mantener la familia, la mayoría estamos todos separados y vueltos a casar, y vueltos a tener otras parejas, ¿me entendés? Y como en su tiempo, lo que vos ganabas en el Cose no alcanzaba, la mayoría de los operadores trabajaba como patovicas y continuaron con esa modalidad a pesar que ya ganaban bien, pero continuaban, no podían dejar esa vida, hay muchos que aún siguen haciendo esa vida, te imaginás, no hay familia que aguante, que resista... de los más viejos, de los más nuevos no, están como más tranqui...".(Entrevista a operador).

" (...) es que ganás muy bien, pero cuando te jubilás es lo mínimo, entonces tuviste una mala calidad de vida laboral y tenés una mala calidad de vida después, cuando te

\footnotetext{
${ }^{13}$ Nota: "Quedar como el ekeko" hace referencia a la imagen del Dios de la abundancia, Ekeko, que remite a llevar muchas cosas superpuestas, como ropa o cargar con elementos.
} 
De Prácticas y discursos/ Universidad Nacional del Nordeste/ Centro de Estudios Sociales

jubilás; entonces el índice es 5 años, después de jubilado el nivel de vida que tenés es muy corto, así es".(Entrevista a operador).

"Yo estuve antes del motín de octubre del año 2012, de ese motín, revuelta o como lo llamemos, nosotros tuvimos muchas denuncias, incluso hasta con filmaciones. No sé por qué cuando fue a la asesoría letrada, terminaron absolviendo a dos o tres, sí que les llegaban a insultar y pegar, directamente a uno le partió tres veces un palo de escoba en las piernas, no sé qué problema habrá tenido en su casa o en su familia, que venían así; venían y se las desquitaban adentro, que esa es una política que no se dio en la DINAF, en el SRPJ en su momento. Una política de ver la salud mental de las personas que tenían trabajando con niños y con estos niños. No tenés nada de eso, vos decías qué te está pasando, en el penal, en la penitenciaría provincial sí se dio, porque hubieron dos o tres suicidios de operadores que habían tenido muchos conflictos familiares, entonces ahí implementaron como un sistema de atención al penitenciario, atención de salud mental al penitenciario".(Entrevista a representante gremial).

El proceso de trabajo de los operadores se realiza en el encierro, en este contexto que evidencia la segregación y fragilización de los cuerpos de los trabajadores y que se expresa en sus padecimientos físicos, familiares, psíquicos y en sus adicciones. Los trabajadores son parte del dispositivo de encierro y a su vez lo padecen; situaciones similares tienen los trabajadores penitenciarios. La invisibilización del sufrimiento y de la consecuencia de este trabajo en la salud y en la cotidianeidad de los trabajadores es evidente porque no existe ni desde la institución, ni desde las demandas del sindicato ninguna medida preventiva o de atención psicológica o interdisciplinaria que los asista para mejorar su vida familiar y laboral.

\section{Los cambios en la organización del trabajo: el control}

"Se pasó de casi 400jóvenes en el 2002 a un promedio de 100 ahora (2012), con lo cual quiere decir que la organización del trabajo y no solamente la organización cuantitativa, sino cualitativa había cambiado sustancialmente; las condiciones de trabajo, desde la perspectiva del laburante, habían mejorado sustancialmente, lo que no se había modificado, lo que queda más en evidencia, son aquellos laburantes que 
De Prácticas y discursos/ Universidad Nacional del Nordeste/ Centro de Estudios Sociales

tienen algunas prácticas complicadas, y esto es una cuestión más allá de tecnología de manejo de situaciones, no es lo mismo manejar un sector con 100 pibes que con 30. Las 'camas o cuchetas que golpean', 'las duchas que tienen pisos movedizos' y 'los pibes agresivos' que trompean a todos los demás, se reducen, entonces, cuando aparece un pibe golpeado, ya las cuchetas estaban domadas, los pisos estaban fijos y los pibes que tenían compulsión de golpear a sus compañeritos de banco no justifican los golpes o heridas de los jóvenes, se reducen más las posibilidades y van quedando más en evidencia. A parte se empieza a incorporar una tecnología que atenta contra estas prácticas, que es el tema de las cámaras, que si bien eran muy pocas, algunos no habían advertido que las cámaras existían, más allá que eran ostensiblemente visibles. Entonces se empieza a producir una serie de sumarios; que lleva incluso a la exoneración".(Entrevista a responsables de la Dirección).

Es un contexto que visibiliza las relaciones de poder en cada uno de los ámbitos, en cada una de las prácticas. Los cambios en el paradigma de derechos posibilitan diferentes instancias antes de la internación, como son las medidas alternativas a la privación de la libertad. Así disminuye el número de jóvenes a cargo de cada operador y no es el hacinamiento o que sean muchos jóvenes lo que incita a una convivencia más conflictiva, sino que los golpes muestran el castigo corporal a los mismos, dejando al descubierto mecanismos represivos y de control.

Las denuncias y quejas cruzadas por agresión y malos tratos entre jóvenes y operadores son constantes. Los castigos son diversos y también parte de lo no dicho de los dispositivos de encierro, como por ejemplo restringirles los movimientos, dejarlos "engomados" -encerrados-, no llevarlos a las actividades educativas, deportivas, talleres que se cursan en la institución.

Un entrevistado del área de Dirección de la DRPJ decía: "(...) la pretensión era que el derecho del trabajador fuese superior al derecho del Estado, a la obligación estatal. Esta era la situación, yo quiero sancionar, "yo quiero definir cuándo se sanciona y no quiero que nadie me revise la sanción, porque yo soy operador terapéutico; entonces cual es el tema, que si a mí me revisan mi decisión, lo que me están haciendo es desautorizarme", se desautoriza y genera un caos. Yo soy el orden, el orden está 
De Prácticas y discursos/ Universidad Nacional del Nordeste/ Centro de Estudios Sociales

garantizado en que el tipo que está de guardia ejerza el poder absoluto. La suma del poder público, es la suma del poder público, "yo tengo que aplicar la sanción", yo soy el único que la puede revisar, soy el único que puede agravarla o aliviarla, esto es, el Estado soy yo, pero es un cuestionamiento que llegó a niveles de absurdos, de esa naturaleza, llegó a no vamos a trabajar hasta que, no vamos a tomar la guardia hasta que nos digan que nosotros podamos sancionar y no van a revisar nuestra sanción; no era solamente discursivo, sino que lo llegaron a poner en el cuerpo, yo no trabajo, nadie va a trabajar, si el que trabaja no puede sancionar y sin que sea revisada la sanción".(Entrevista a responsables de la Dirección).

Son los operadores en sus prácticas quienes llevan a cabo la ejecución de la pena, quienes detentan el poder en esta relación y que en estas instituciones están, como dice Bialakowsky (2003), legalizadas y estandarizadas.

\section{Consideraciones finales}

El conflicto que se produjo con el motín de octubre de 2012 dejó al descubierto el antagonismo operadores/jóvenes, evidenciado en los cuerpos heridos de operadores e internos por agresiones cruzadas, en el rol de las instituciones y la desafección social casi total por este problema de parte de funcionarios y la sociedad en su conjunto.

La nueva gestión punitiva propugnada por el paradigma de protección de derechos tensiona permanentemente tanto los aspectos legales como las prácticas mismas en la institución. La aplicación de la ley 26.061 conlleva especificidades en cuanto a la internación de jóvenes en conflicto con la ley, siendo esta la última instancia y priorizándose la aplicación de medidas alternativas a la privación de la libertad, como también el rol socioeducativo de las instancias de los sistemas cerrados.

Las prácticas cotidianas que moldean relaciones entre operadores y jóvenes en conflicto con la ley que están internados en la DRPJ coloca al operador y regente como quien ejecuta la pena y, a su vez, es quien cuida y contiene, construye vínculos con los jóvenes, educa y como todo trabajador tiene demandas específicas en cuanto a la organización de su trabajo. 
De Prácticas y discursos/ Universidad Nacional del Nordeste/ Centro de Estudios Sociales

El discurso y las prácticas punitivas siguen vigentes sin importar el nombre del nuevo paradigma de derechos o los cambios de denominación de las instituciones. Así lo devela el discurso de los operadores, quienes en su mayoría justifican su accionar, reclaman por sus derechos y sobre todo aquellos que cometen hechos ilícitos, piden no ser observados en sus prácticas ni en sus acciones.

El motín dejó al descubierto una situación sensible relacionada con la organización del trabajo de los operadores y el control a sus prácticas. Una de las causas que disparó el conflicto fue la exoneración, por primera vez, de un operador por ejercer violencia contra uno de los jóvenes allí internados. A esto también se llega por una falta de intervención de los organismos de control de otras áreas del Estado. El motín pone de manifiesto que recién después de un reclamo conjunto de organizaciones de derechos humanos de la provincia y que se plasma en un pedido de habeas corpus colectivo, intervienen otras instituciones de fiscalización y control.

Desde el sindicato se reunieron con integrantes del Poder Judicial y no se hicieron sumarios, quedó una sensación de impunidad de que todo es discutible, todo es provisorio. Así confrontan prácticas que no son acordes a la ley, un Poder Judicial que no sanciona y la naturalización de que todo ahora está bien.

Este acontecimiento refleja claramente el conflicto social, que convierte a ciertos grupos -en este caso jóvenes, pobres, transgresores- en parte de las poblaciones extinguibles en las cuales los derechos son de segundo nivel, lo cual dificulta todo el proceso de ciudadanización e inclusión. Los incuestionables avances conceptuales y legislativos evidencian en su implementación concreta prácticas gubernamentales que ponen de manifiesto las tensiones, contradicciones y el conflicto de una sociedad que excluye mediante prácticas de gestión punitivas.

La misma dominación organizativa de estas instituciones reproduce el conflicto social que se hace visible en las prácticas de los trabajadores y en el sufrimiento de cada uno de los jóvenes, lo cual se legitima con silencios sociales sobre estas poblaciones excluidas. Los operadores trabajan cotidianamente sobre la urgencia, sobre lo dado, naturalizando dispositivos institucionales, ya que no hay un proceso reflexivo sobre las prácticas, respecto a los mecanismos de dominación, disciplinamiento y castigo que 
De Prácticas y discursos/ Universidad Nacional del Nordeste/ Centro de Estudios Sociales

ellas posibilitan. De las entrevistas realizadas surge que en lo cotidiano es muy compleja la relación entre quien cuida, vigila y quien está privado de la libertad. El que cuida tiene un doble rol: de operador y de represor. Esto que se evidencia en el proceso de trabajo de los operadores también los coloca a ellos en una situación de vulnerabilidad y fragilización.

La sociedad crea instituciones para hacer efectiva la pena a los transgresores, genera leyes, protocolos, etc., pero la ejecución de la pena es realizada por personas, trabajadores, sus prácticas no son solo excesos, abusos de autoridad individuales, personales, son parte del dispositivo punitorio. Cuando por alguna razón este es cuestionado, se individualizan en un sujeto los "excesos", sin que se ponga en cuestión que es la institución y su función las que hacen posible los abusos.

Este caso nos invita a pensar la función y el destino de estos trabajadores, parte de una burocracia especial encargada de la represión y el control de los segmentos de población "delictiva", "peligrosa", "transgresora": policías, penitenciarios, operadores o celadores de la DRPJ. De esta situación, los trabajadores son victimarios y víctimas, nadie puede salir inmune después de trabajar en una institución de control social, consideramos que en tanto trabajadores son parte también de lo que la sociedad decide extinguir, del continuum exclusión-extinción.

\section{Referencias}

Bialakowsky, A. y otros (2003).Procesos sociales de trabajo en instituciones públicas: actores bifrontes. Revista Encrucijada, 23.

Bialakowsky, A. y otros (2005). Núcleos Urbanos Segregados. Proceso de exclusiónextinción social y prácticas institucionales. En Igarzábal de Nistal, J. M. y Wainstein-Krasuk, O. (comp.) Hacia la gestión de un hábitat sostenible. Buenos Aires: Ed. Nobuko-Facultad de Arquitectura y Urbanismo, Universidad de Buenos Aires (FADU-UBA)-Centro de Información Metropolitana-Instituto Superior de Urbanismo, Territorio y el Ambiente-Centro de Estudios del Hábitat y la Vivienda (CEHyV). 
De Prácticas y discursos/ Universidad Nacional del Nordeste/ Centro de Estudios Sociales

Bialakowsky, A. L. (2008). Prácticas gubernamentales en la regulación de poblaciones extinguibles. Colección CLACSO-CROP. Disponible en: http://bibliotecavirtual.clacso.org.ar/clacso/clacsocrop/20120620084925/07biala.pdf

Daroqui, A. y otros (2012).Sujetos de Castigo. Santa Fe: Homo Sapiens.

Dirección de Promoción y Protección de Derechos (2010). Construyendo una nueva Institucionalidad: Manual de Procedimientos. Ley 26.061. Ministerio de Desarrollo Humano, Familia y Comunidad. Gobierno de Mendoza.

Guemureman, S. y otros (2010). Dispositivos de privación de libertad y lógica de gobierno intramuros para adolescentes: laberintos de derechos sin sujetos. En II Reunión Nacional de Investigadores en Juventudes, Salta.

Ley 26.061 (2005). Ley de Protección Integral de los Derechos de las Niñas, Niños y Adolescentes.

Ley 6.354 (1995). Ley del Niño y Adolescente de la Provincia de Mendoza.

Ministerio de Desarrollo Social y DDHH de Mendoza (2013). Manual de Procedimiento de la Unidad de Internación.

UNICEF Argentina-SENAF (2008). Adolescentes en el Sistema Penal: Situación actual y propuestas para un proceso de transformación. Buenos Aires: Universidad Nacional de Tres de Febrero. Fondo de la Naciones Unidas para la Infancia y Secretaria Nacional de Niñez, Adolescencia y Familia.

Zaffaroni,E. (2011). Prólogo. En Marcón, O. (ed.)Jóvenes en situación de conflicto penal: ¿cómo relatan sus historias?: análisis y prospectivas desde la Justicia Juvenil Restaurativa. Buenos Aires: Teseo.

Zambrano, S. (2009). Entrevistas a jóvenes en contexto de encierro. En García Ocanto, S. (ed.)El sistema de responsabilidad Penal Juvenil de la provincia de Mendoza: Estrategias para la resocialización de los jóvenes en conflicto con la Ley. Mendoza: UNCuyo.

Zambrano, S. (2012). La educación en contextos de encierro en DRPJ (ex COSE) en Mendoza. Tesis de Grado de la Licenciatura en Trabajo Social. Mendoza: FCPySociales, UNCuyo (inédito). 